\title{
The abnormal skin structure of newly born Wistar rat maternally-treated with aspartame: histological and immunohistochemical study
}

\author{
Abd El-Fattah BM El-Beltagy ${ }^{1}$ and Heba AI El-Ghawet ${ }^{2}$ \\ ${ }^{1}$ Zoology Department, Faculty of Science, Damanhour University; ${ }^{2}$ Department of Zoology, Faculty of Science, \\ Mansoura University, Egypt
}

\begin{abstract}
Article history
Received:10 May, 2016

Revised: 15 Jun, 2016

Accepted: 20 Jun, 2016

Abstract

Aspartame is an artificial sweetener and flavour enhancer in low-calorie, with sweetness about 200 times higher than sugar. The present study aims to declare the effect of aspartame on the histological and immunohistochemical structures of the skin in Wistar albino rat neonates. Twelve pregnant female Wistar-albino rats were separated into two groups, a control and an experimental group $(n=6)$. The first group was orally administered a daily dose of saline solution $(0.5 \mathrm{ml})$ free from the $4^{\text {th }}$ day of pregnancy till birth. The second group was orally administered $40 \mathrm{mg}$ aspartame $/ \mathrm{kg}$ body weight for the same period. Samples from the dorsal abdominal skin of one dayold neonatal rats were fixed in $10 \%$ buffered neutral formalin and prepared routinely for histopathological and immunohistochemical investigations. Other samples were taken immediately, frozen and prepared for flow cytometric investigation of annexin V. Compared with the control group, the skin of aspartame treated neonatal rats showed a significant decrease $(\mathrm{P}<0.05)$ in the epidermal and dermal thickness as well as hair follicle depth. The epidermis appeared foliated with obvious hypertrophied cells; other dispersed cells had pyknotic nuclei and vacuolated cytoplasm. The dermis showed less condensed connective tissue, degenerated sebaceous glands and scarcely irregular hair follicles. The immunohistochemical investigations of aspartame neonatal rats showed intense positive reactions for Caspse-3, P53 and vascular endothelial growth factor (VEGF) but a negative to weak reaction for Caspase-7 and CK17 antibodies. Furthermore, the flow cytometric analysis of the annexin $\mathrm{V}$ revealed a significant increase in the apoptotic area corresponding to upper right (UR) and lower right (LR) area. In conclusion, the consumption of aspartame by mother rats during gestation leads to remarkable histological lesions and increased risk of apoptosis in the skin of their neonatal pups.

Keywords: Aspartame; skin; neonatal; histopathology; apoptosis
\end{abstract}

To cite this article: Abd El-Fattah BM El-Beltagy and AI El-Ghawet H, 2016. The abnormal skin structure of newly born Wistar rat maternally-treated with aspartame: histological and immunohistochemical study. Res. Opin. Anim. Vet. Sci., 6(5): 151-157.

\section{Introduction}

Aspartame (1- aspartyl 1-phenylalanine methyl ester) is a non-nutritive sweetener that is vastly used in many food products and drinks. Aspartame is approximately 200 times sweeter than sugar (Rencuzogullari et al., 2004). Aspartame is a low calorie choice which offers an alternative sweetening

*Corresponding author: Abd El-Fattah BM El-Beltagy, Zoology Department, Faculty of Science, Damanhour University, Damanhour, Egypt, E-mail: beltagyaaa@yahoo.com; Tel: 01022603729 
for people who should or need to control their sugar intake. The safety of aspartame remains controversial in spite of there are many studies on its risks. Millions of people consume a variety of products containing aspartame such as beverages, quick breakfasts, sweets, inhale mints, some chewing gum, drugs and vitamins (Alleva et al., 2011). Aspartame is mainly metabolized in the intestines and absorbed as phenylalanine $(50 \%)$ and aspartic acid (40\%) along with methanol (10\%) (Boehm et al., 1984). Stegink (1987) found that after aspartame absorption, the concentrations of its metabolites are elevated in the blood. Previous studies revealed that a relatively little amount of aspartame can significantly elevate methanol levels (Davoli, 1986) and further oxidized to formaldehyde and formate (Trocho et al., 1998). Castro et al. (2002) added that methanol intoxication could induce mitochondrial damage and increased microsomal activity and consequently increased liberation of oxygen radicals.

Later studies by Humphries et al. (2008) indicated that chronic exposure to aspartame may cause headache, epileptic tits, and brain tumours as well as blurred vision, eye problems, Alzheimer, insomnia, numbness, nausea, slurred speech, personality changes, energy loss, hyperactivity, hearing problems, neurological and behavioural disorders. Moreover, most reports on aspartame have been carried out to clarify its toxicity mechanism (Bergstrom et al., 2007) and development of cancer (Soffritti et al., 2006; Gallus et al., 2007). Several studies on experimental animals confirmed that aspartame induces harmful effects on the different body organs. The studies on rodents revealed that radiolabelled aspartame accumulates in the brain, liver, kidneys and other body tissues after consumption (Trocho et al., 1998). Furthermore, oral aspartame consumption at $75 \mathrm{mg} / \mathrm{kg}$ body weight has been found to induce oxidative stress in the brain and liver (Ashok et al., 2013) while at $40 \mathrm{mg} / \mathrm{kg}$ body weight, it causes oxidative stress in the brain (Mourad and Noor, 2011), liver and kidney (Mourad, 2011) and immune system (Choudhary and Devi, 2014). Soffritti et al. (2004) confirmed that, aspartame is a multipotential carcinogenic factor when given at a daily oral dose of $20 \mathrm{mg} / \mathrm{kg}$ body weight. Other studies revealed that consumption of aspartame could induce histopathological degenerative changes in the liver of male rats (Soliman et al., 2013), parotid salivary glands of male rats (El-Sakhawy and Saeid, 2014) and on kidney and testis (Hozayen et al., 2014).

Apoptosis can be initiated by signals arising from the activation of death receptor-mediated (extrinsic) or mitochondrial-mediated (intrinsic) signalling pathways. Extrinsic apoptotic signalling arises from the activation of cell surface death receptors belonging to the protein family of tumour necrosis factor receptors (Itoh and Nagata, 1993). The binding of such receptors with its appropriate ligand, can result in activation of caspase 8 , activating downstream effector caspases (e.g., caspases 3,6 , and 7), resulting in apoptosis (Chinnaiyan et al., 1995; Varfolomeev et al., 1998). Horio et al. (2014) found that aspartame could induce apoptosis in pheochromocytoma cells of the adrenal medulla through activation of caspaseses 8 and 9 and cytochrome $\mathrm{C}$ of mitochondrial pathway. Another study revealed that aspartame could inhibit the apoptosis process in cancer cells by down-regulation of mRNA expression of tumour suppressor gene $\mathrm{p} 53$, and proapoptotic gene bax. It up-regulates anti-apoptotic gene bcl-2 mRNA expression (Pandurangan et al., 2016).

Reviewing the literature, there is little work focused on the direct effects of aspartame on the skin. Accordingly, the present study was attempted to evaluate the histological and immunohistochemical alterations in skin of newly born Wistar rat maternallytreated with aspartame.

\section{Materials and Methods}

\section{Aspartame-treatment}

Aspartame was purchased from Amyria Pharmaceutical Company, Cairo, Egypt. It was available in the form of tablets, each tablet contained $20 \mathrm{mg}$.

\section{Experimental design}

Fifteen healthy Wistar rats (12 females and 3 males', average of $180 \pm 20 \mathrm{~g}$ ) were used in the present work. The animals were maintained under well aerated room with $12 \mathrm{~h}$ light and room temperature $25^{\circ} \mathrm{C}$. All rules applying to animal safety and care were observed. The mating was done between male and female by a ratio 1:3. After ensuring of pregnancy (by observation of vaginal plugs), the pregnant females were kept in separate cages and divided into two groups $(n=6)$; control received saline-free $(0.5 \mathrm{ml})$ aspartame and experimental group dosed orally with $0.5 \mathrm{ml}$ containing $40 \mathrm{mg}$ aspartame $/ \mathrm{kg} /$ day from the $4^{\text {th }}$ day of pregnancy till birth (Abd Elfatah et al., 2012).

After birth, the neonates of both control and experimental groups were anesthetized with diethyl ether and sacrificed. Their dorsal abdominal skin was removed and separated and investigated as follows:

\section{Morphometric studies}

The epidermal, dermal thickness as well as the hair follicle depth was measured in histologically prepared sections by using linear ocular micrometer.

\section{Histological investigations}

Skin specimens were fixed in $10 \%$ neutral buffered formalin solution ( $\mathrm{PH}$ 7.4) for 24-48 h. The tissues were then dehydrated in ascending series of alcohol 
solution, cleared in xylene and mounted in molten parablast at $58-62^{\circ} \mathrm{C}$. Five micrometer thick vertical sections were cut, stained with haematoxylin and eosin, and examined under bright field microscope.

Immunohistochemical labelling of caspase-3, caspse7, P53, vascular endothelial growth factor (VEGF) and cytokeratin 17 (CK17)

Five $\mu \mathrm{m}$ thick paraffin sections were cut, mounted onto positively charged slides. After overnight at $65^{\circ} \mathrm{C}$, tissue sections were de-paraffinized in xylene and hydrated in descending grades of alcohol. Endogenous peroxidase activity was inhibited by incubation of tissue sections in $3 \% \mathrm{H}_{2} \mathrm{O}_{2}$ in methanol for $10 \mathrm{~min}$ at room temperature. The tissue sections were retained at normal room temperature and processed for antigen retrieval by digestion in $0.05 \%$ trypsin (PH 7.8). The tissue sections were incubated at $40^{\circ} \mathrm{C}$ for $40 \mathrm{~min}$. with polyclonal rabbit anti-caspase-3 antibody (1:1000 dilutions, Phar Mingen, San Diego, CA, USA), polyclonal rabbit anticaspase-7 antibody (1:50 dilution, Danvers, MA), with monoclonal anti-P53 antibody (clone DO-7 Dako), mouse polyclonal anti-VEGF antibody (1:100 dilutions, Cat. No. RB-9031-P) and monoclonal antibody against cytokeratin 17 (1:100, Cat. No. MA5-15534). After washing with buffer, slides were incubated with a secondary biotin linked anti-mouse antibody for $50 \mathrm{~min}$ at room temperature; and with the streptoavidin-peroxidase complex for 50 min. The sections were then washed with distilled water, incubated with developing solution (diaminobenzidine-hydrogen peroxide; DAKO), and counterstained with hematoxylin. Finally, the sections were examined under bright field light Olympus microscope with a digital Canon camera.

\section{Flow cytometry for annexin $\mathbf{V}$}

Flow cytometric analysis was performed on FACScan (Becton Dickinson) using standard settings: fluorescence 1(FL1), 4 decades (logarithmic), detector $648 \mathrm{~V}$, logs amplifier, compensation $1.1 \%$; flouresence 2, 4 decades (logarithmic), detector $496 \mathrm{~V}, \log$ amplifier, compensation $22.8 \%$. Data analysis was performed using lysis of software (Becton Dickinson).

Biopsies from the skin of the studied groups were taken, and the cell suspension was prepared with TrisEDTA buffer (pH7.4) (Sigma-Aldrich Co.). The cell suspension was fixed in ice-cold $96-100 \%$ ethanol (Sigma) at $4^{\circ} \mathrm{C}$ overnight, centrifuged at $1,500 \mathrm{rpm}$ for $10 \mathrm{~min}$, and then re-suspended in PBS containing 50 $\mu \mathrm{g} / \mathrm{ml}$ propidium iodide (PI) (Sigma-Aldrich Co.). For each sample, since analysis was based on the measurement of 10000 cells. Single cell suspensions were prepared from the skin for at least six neonates of rats and 1.5-3 $\times 10^{6}$ cells were stained for expression of the designated lineage markers.
Skin cells apoptosis was assessed by flow cytometry using an annexin V FITC/ PI staining kit (pharmingen, Becton Dickinson Co., San Digo, CA, USA). After $48 \mathrm{~h}$ of transfection, the cells were harvested, washed twice in $\mathrm{PBS}(\mathrm{NaCl} 40 \mathrm{~g}, \mathrm{KCl} 1 \mathrm{~g}$, $\mathrm{KH}_{2} \mathrm{PO}_{4} 1 \mathrm{~g}, \mathrm{Na}_{2} \mathrm{HPO}_{4} 4.6 \mathrm{~g}$ and distilled water to make up to $51 \mathrm{ml} ; 4^{\circ} \mathrm{C}$ ). The cells were re-suspended in the binding buffer (10Mm HEPES/NaOH pH 7.4, 140Mm $\mathrm{NaCl}, 2.5 \mathrm{Mm} \mathrm{CaCl}_{2}$ ). The samples were stained with fluorescent isothiocyanate-conjugated annexin V (Annexin V-FITC), mixed gently and incubated for 15 min at room temperature in the dark, and then washed with binding buffer and analyzed by flow cytometry (FACS Caliber; Becton Dickinson) using Cell Quest software (Becton Dickinson, San Jose, CA,USA).

Data was recorded as mean \pm standard error. Statistical analysis was carried out by one way ANOVA. Significant difference was carried out at $\mathrm{P}<0.05$.

\section{Results}

\section{Morphometric analysis of skin}

In comparison with control, the skin of aspartame treated neonatal rats showed a significant decrease $(\mathrm{P}<0.01)$ in the mean value of epidermal and dermal thickness as well as the depth of their hair follicles (Fig. $1)$.

\section{Histological observations}

In control, the light microscopic examination revealed that the skin consisted of an upper epidermis and lower dermis. The epidermis was composed of three regularly arranged layers from inside outwards as follows: stratum germinativum, stratum graulosum and stratum corneum. The stratum germinativum was composed of 1-2 layers of densely packed cuboidal cells with centrally located nuclei. The stratum granulosum was composed of 2-3 layers of darkly stained keratinocye cells. The outermost layer, stratum corneum appeared faint and consisted of 3-5 layers of densely packed dead cells. The dermis was relatively thicker than the epidermis and exhibited homogenate connective tissue with vertically oriented hair follicles and unbranched sebaceous glands (Fig. 2A \& A1). The cross histological sections of hair follicles showed a normal structural pattern of hair layers showing outer hair root, middle hair cortex and inner hair medulla (Fig. 2 A2).

In compared with control, the histological sections of skin in aspartame treated group showed remarkable histological alterations in both the epidermal and dermal layers. The epidermal layer was relatively thick, foliated with obvious hypertrophied cells in both the stratum germinativum and stratum granulosum. Other dispersed cells had pyknotic nuclei and vacuolated cytoplasm. The dermal layer showed less condensed 


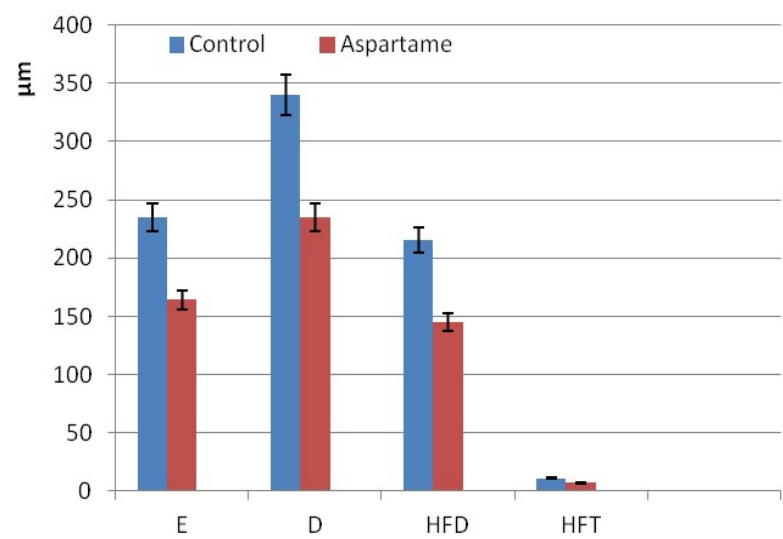

Fig. 1: The epidermal thickness (E), dermal thickness (D), hair follicle depth (HFD) and hair follicle thickness (HFT) of control and aspartame group. Each column represents the mean $\pm \mathrm{S}$.E of five replicates. In compared with control, all morphometric data showed significant decrease $((\mathrm{P}>0.01)$ in aspartame-treated group.

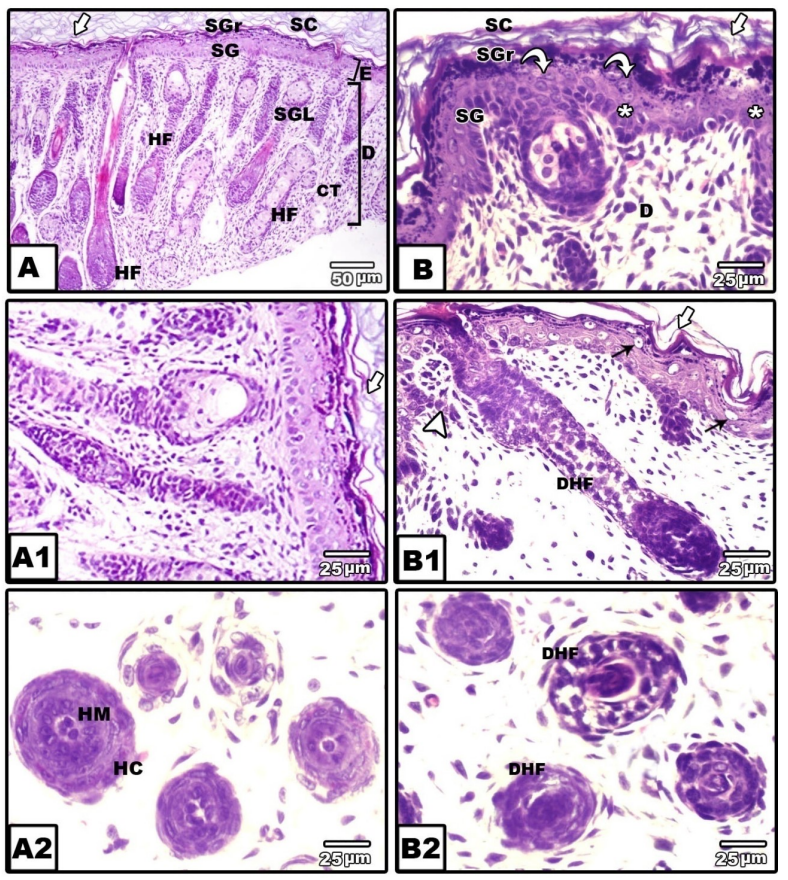

Fig. 2: Photomicrographs through histological vertical sections of skin of control (A-A2) and aspartame (B-B2) neonates. In aspartame treated group, the skin sections showing obvious accumulation of keratin (white arrow), cellular pyknosis (curved arrow), hypertrophied cells (star), cytoplasmic vacuolation (black arrow), degenerated hair follicle (DHF) and less condensed connective tissue with damaged sebaceous gland (arrow head). H\&E $\mathrm{X}$ : 400 Abbreviations: E; epidermis, D; dermis, SC; stratum corneum, SGr; stratum granulosum, SG; stratum germanitivum, HF; hair follicle, CT; connective tissue. connective tissue with degenerated sebaceous glands and scarcely irregular hair follicles. Furthermore, the lining cell layers of hair follicles appeared inconsistent with hetrochromatic nuclei (Fig. 2 B-B2).

\section{Immunohistochemical observations}

In the control group, the skin sections exhibited negative to very weak immune expression for anticaspase-3, 7, P53, and moderate immunoreactivity for both VEGF and CK17 antibodies (Fig. 3 A-E). On the other side, the skin sections of aspartame treated neonatal rats revealed a strong positive immunohistochemical reaction for anti-caspase-3, P53 and VEGF antibodies, but negative for weak expression for anti-caspase-7 and CK17 antibodies. The immnoreactivity for all antibodies was markedly localized in the cells of stratum germinativum stratum granulosum dermal connective tissue and hair follicles (Fig. 3 A1E1).

\section{Flow cytometric analysis of annexin $\mathbf{V}$}

In compared with control, the mean percentage of skin apoptosis indicated by flow cytomtric analysis of skin annexin $\mathrm{V}$ in upper right (UR) and lower right (LR) was significantly higher $(\mathrm{P}<0.05)$ in aspartame treated neonatal rats (Fig. 4).

\section{Discussion}

Many existing reports, which are available, stated that aspartame releases toxic metabolites during metabolism, in which methanol is considered to be one. Several studies approved that the toxicity of aspartame is mainly due to the accumulation of methanol in the vital body tissues in the form of formaldehyde and formic acid (Camfield et al., 1992; Trocho et al., 1998; EFSA, 2006; Ashok et al., 2013; El-Sakhawy and Saeid, 2014). The present study highlights the toxic effects of aspartame metabolites on the skin of neonatal rats.

In the current work, several deleterious histological alterations were recorded in the skin sections of aspartame treated neonatal rats. Such alterations were included remarkable reduction in the epidermal and dermal thickness, epidermal keratinization, hypertrophied cells, pyknotic nuclei and vacuolated cytoplasm, degenerated sebaceous glands and hair follicles. However, there were apparent reductions in the density and depths of hair follicles. It has been reported that formic acid has toxic effects on the epithelial tissues, especially of the skin; respiratory system, gastrointestinal tract and urinary system (Nilsson et al., 1998; Thrasher et al., 2001). Banihashemi et al. (2011) supposed that decreased hair follicles may be attributed to irritative or dehydration properties of formic acid that has penetrated the 


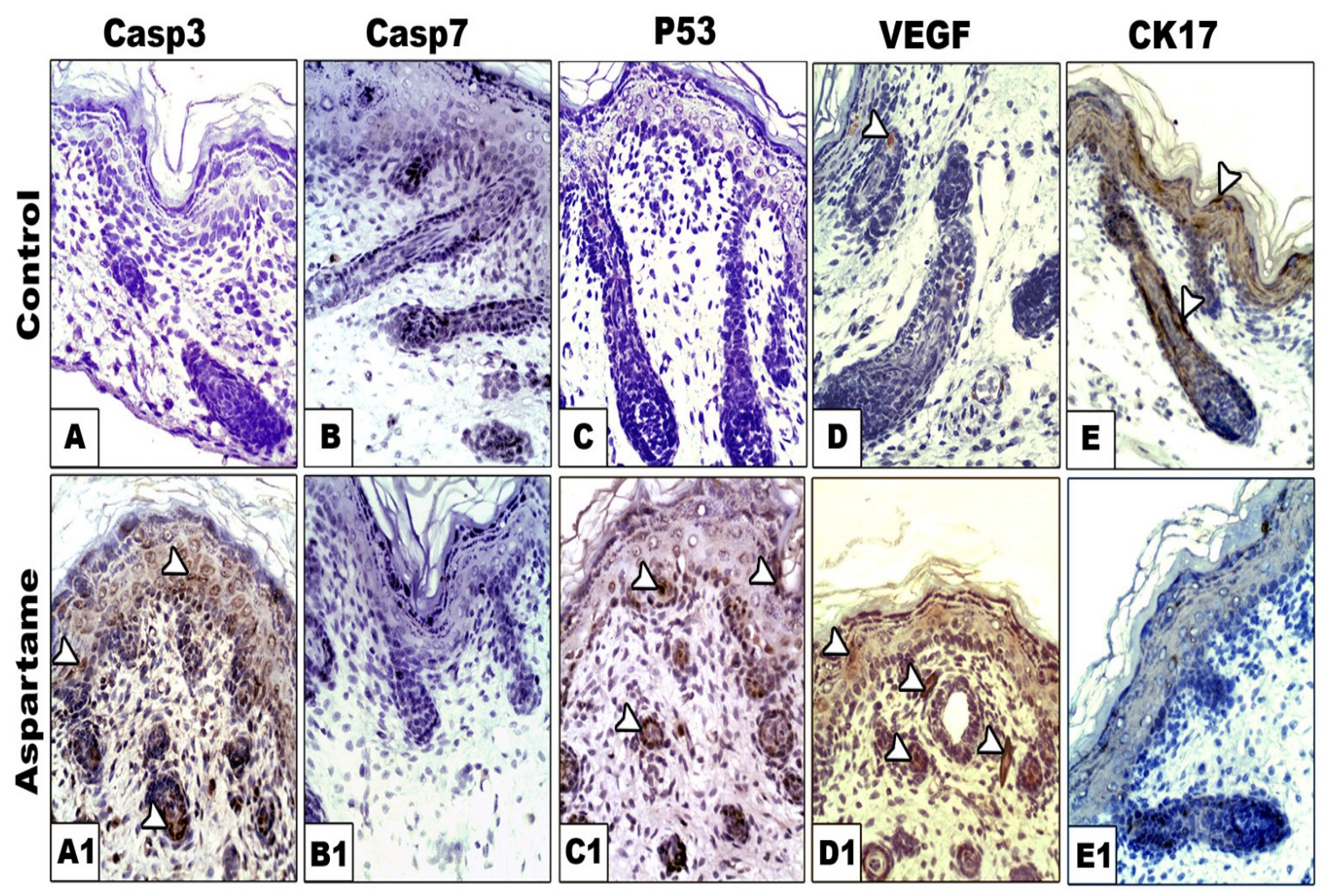

Fig. 3: Photomicrographs of formalin fixed paraffin embedded sections of skin of control (A-E) and aspartame (A1-E1) neonatal Wister rat's immunohistochemically stained with Caspase-3, Caspase-7, P53, VEGF and CK17 antibodies. In compared with the control, the aspartame group showing strong positive immune expression for capase 3, P53, VEGF but weak immune reaction for caspase 7 and CK17 antibodies. (IHC technique X: 400). The arrows heads indicate the degree of immunoreactivity
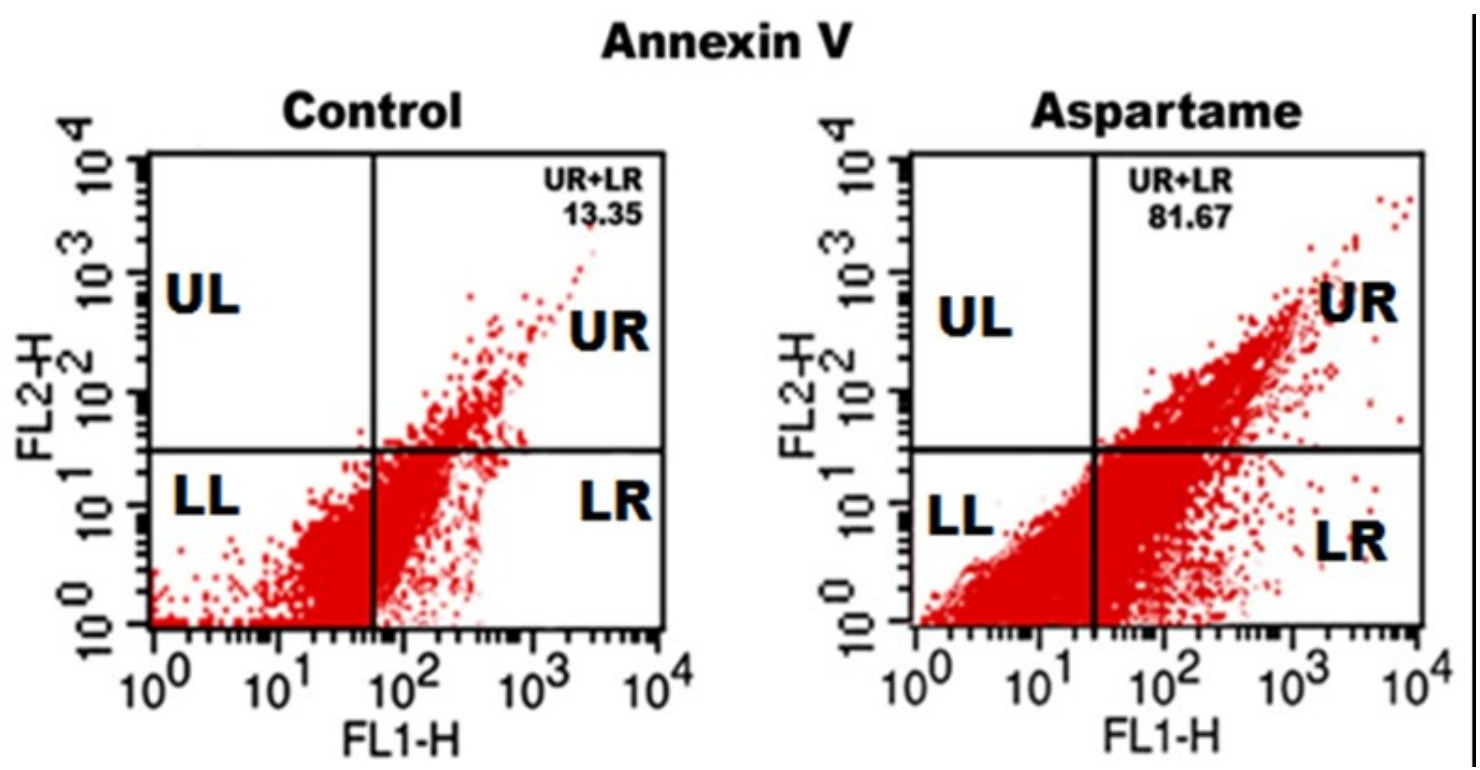

Fig. 4: Flow cytometry chart of annexin $V$ of skin of control and aspartame neonatal rats. a significant increase in the mean percentage of apoptosis in the upper right (UR) and lower right (LR) of aspartame in comparing with the corresponding bands of control but nonsignificant difference among the two groups in the upper left (UL) and lower left (LL). 
medullary core of hair follicles and sebaceous glands resulting in deleterious histological changes. Epidermal cellular hypertrophy and vacuolation may be considered as a type of cellular defence mechanism against the inflammatory process induced by aspartame metabolites ( Ali et al., 2014) as well as a source of accumulating toxic agents interfering with its biological interactions in cell metabolism (Cheville, 2009).

In the present work, evaluation of skin sections of aspartame treated neonatal rat's revealed immune positive expression for apoptotic markers caspase-3, P53, but a negative expression for caspse-7, low expression for VEGF and immunoreactivity of CK17. Previous studies revealed that aspartame metabolites could induce the apoptotic process via activation of caspase-3 and P53 (Horio et al., 2014) and increased angiogenesis through activation of VEGF (Alleva et al., 2011). Further confirmation of our results, the flow cytometric analysis of annexinV was elucidated a significant increase in the mean percentage of apoptotic cells in the UR and LR area of the obtained FACScan reading value. Also, it has been reported that activation of caspase- 3 is accompanied by inhibition of CK17 activity (Badock et al., 2001). Usanmaz et al. (2002) explained that formic acid as a major metabolite of aspartame increases the liberation of free oxygen radicals and inflammatory mediators IL-6 and this accelerates the processes of angiogenesis and apoptosis. Cytokeratin 17 is a significant protein marker for keratin type I formation (Divani and Kalodimos, 2010). McGowan and Coulombe (1998) declared that decreased expression of CK17 leads to impairment in mechanical stability of skin morphogenesis and hair follicles development and consequently induce apoptosis. This study establishes that aspartame metabolites can induce histopathological changes and apoptosis in the skin.

\section{Conclusion}

Based on our findings, consumption of aspartame by pregnant rats leads to various degrees of skin lesions in their neonates. Such lesions were attributed to aspartame metabolites and represented by disturbances in skin histogenesis, stimulation of apoptosis and angiogenesis.

\section{References}

Abd Elfatah AA, Ghaly IS, Hanafy SM (2012) Cytotoxic effect of aspartame (diet sweet) on the histological and genetic structures of female albino rats and their offspring. Pak J Biol Sci 15(19): 90418.

Ali AA, El-SeifyGH, El Haroun HA, Soliman MA (2014) Effect of monosodium glutamate on the ovaries of adult female albino rats and the possible protective role of green tea. Menoufia Med J 27: 793-800.

Alleva R, Borghi B, Santarelli L, Strafella E, Carbonari D, Bracci M, Tomasetti M (2011) In vitro effect of aspartame in angiogenesis induction, Toxicol Vitro 25(1): 286-293.

Ashok R, Sheeladevi D, Wankhar W, Wankhar W (2013) Long-term effect of aspartame on the liver antioxidant status and histopathology in Wistar albino rats. Biomed Prev Nut 4(2): 299-305.

Badock V, Steinhusen U, Bommert K, WittmannLiebold B, Otto A (2001) Apoptosis-induced cleavage of keratin 15 and keratin 17 in a human breast epithelial cell line. Cell Death Differ 8(3): 308-15.

Banihashemi M, Rad AK, Yazdi SA, Rakhshande H, Ghoyonlo VM, Zabihi Z, Yousefzadeh H (2011) Evaluation of the effect of formic acid and sodium formate on hair reduction in rat. Clin Cosmet Investig Dermatol 4: 69-72

Bergstrom BP, Cummings DR, Tricia A, Skaggs TA (2007) Aspartame decreases evoked extracellular dopamine levels in the rat brain: an in vivo voltammetry study. Neuropharmacology, 53: 967-74.

Boehm MF, Bada JL (1984) Racemization of aspartic acid and phenylalanine in the sweetener aspartame at $100^{\circ} \mathrm{C}$. Proc Natl Acad Sci USA 81: 5263-6.

Camfield PR, Camfield CS, Dooley JM, Gordon K, Jollymore S, Weaver DF (1992) Aspartame exacerbates EEG spike-wave discharge in children with generalized absence epilepsy: a double-blind controlled study. Neurology 42: 1000-1003.

Castro GD, Costantini MH, Delgado de layno AM, Castro A (2002) Rat liver microsomal and nuclear activation of methanol to hydroxyl methyl free radicals. Toxicol Lett 129(3): 227-36.

Cheville, N.F. (2009). Ultrastructural pathology: the comparative cellular bas of disease. 2nd ed. USA: Wiley-Blackwell. A John Wiley of Sons Inc.

Chinnaiyan AM, O'Rourke K, Tewari M,Dixit VM (1995) FADD, a novel death domain-containing protein, interacts with the death domain of Fas and initiates apoptosis. Cell 81: 505-512.

Choudhary AK, Devi RS (2014) Imbalance of oxidant antioxidant status by aspartame in the organs of immune system of wistar albino rats, Afr J Pharm Pharmacol 8(8): 220-230

Davoli E, Cappellini L, Airoldi L, Fanelli R (1986) Serum methanol concentrations in rats and in men after a single dose of aspartame. Food Chem Toxicol 24(3): 187-9.

Divani S, Kalodimos, G (2010) Expression of cytokeratins- 8 and 17 as a diagnostic marker of cervical intraepithelial neoplasia. www.onk.ns.ac. rs/Archive 18(3): 88-90. 
El -Sakhawy M, Saeid S (2014) Effect of long term administration of aspartame on the parotid salivary glands of male albino rats. Inter J Adv Res 2(3): 850-857

European Food Safety Authority (EFSA) (2006) EFSA assesses new aspartame study and reconfirms its safety. http://www.efsa.eu.int/science/afc/ afc opinions/1471 en.htm.

Gallus S, Scotti L, Negri E, Talamini R, Franceschi S, Montella M (2007) Artificial sweeteners and cancer risk in a network of case-control studies. Ann Oncol 18(1): 40-4.

Horio Y, Sun Y, Liu C, Saito T, Kurasaki M (2014) Aspartame-induced apoptosis in PC12 cells. Environ Toxicol Pharmacol 37(1): 158-65.

Hozayen WG ,Soliman HAE, Desouky EM (2014) Potential Protective Effects Of Rosemary Extract, Against Aspartame Toxicity In Male Rats 2(6): 111-125.

Humphries P, Pretorius E, Naude H (2008) Direct and indirect cellular effects of aspartame on the brain. Eur J Clin Nutr 62: 451-62.

Itoh N, Tsujimoto Y, Nagata SJ (1993) Effect of bcl-2 on Fas antigen-mediated cell death J Immunol 151(2): 621-7.

McGowan KM, Coulombe PA (1998) Onset of Keratin 17 Expression Coincides with the Definition of Major Epithelial Lineages during Skin Development. J Cell Biol. 1998 Oct 19: 143(2): 469-86

Mourad IM (2011) Effect of aspartame on some oxidative stress parameter in liver and kidney of rats. Afr J Pharm Pharmacol 5(6): 678-682.

Mourad IM, Noor NA (2011) Aspartame (A Widely used Artificial Sweetener) and Oxidative Stress In the Rat Cerebral Cortex Int J Pharm Biomed Sci 2(1): 4-10.

Nilsson JA, Zheng X, Sundqvist K, Liu Y, Atzori L, Elfwing A, et al (1998) Toxicity of formaldehyde to human oral fibroblast and epithelial cells: influences of culture conditions and role of thiol status. J Dent Res 77: 1896-903.

Pandurangan M, EnkhtaivanG, Mistry B, Chandrasekaran M, Noorzai R, Kim KH (2016)
Investigation of role of aspartame on apoptosis process in HeLa cells, Saudi J Biolog Sci doi:10.1016/j.sjbs.2015.06.001

Rencuzogullari E, Tuylu BA, Topaktas M, Ila HB, Kayraldiz A, Arslan M, et al (2004) Genotoxicity of aspartame. Drug Chem Toxicol 27(3): 257-68.

Soffritti M, Belpoggi F, Degli-Esposti D, Lambertini L, Tibaldi E, Rigano A (2006) First experimental demonstration of the multipotential carcinogenic effects of aspartame administered in the feed of Sprague-Dawley rats. Environ Health Perspect 114(3): 379-85.

Soffritti M, Belpoggi F, Padovani M, Lauricia M, Dagli Spositi D, Minardi F (2004) Lifetime carcinogenicity biossay of toluene given by stomach tube to Sprague-Dawley rats. Eur J Oncol 9(2): 91-102.

Soliman HAE, Hozayen WG, Desouky EM (2013) Potential Protective Effects Of Rosemary Extract, Against Aspartame Toxicity In Male Rats. Egyp J Biochem Molec Biol 31(2): 143-158.

Stegink LD (1987) The aspartame story: a model for the clinical testing of a food additive, Am J Clin Nutr 46(1): 204-215.

Thrasher JD, Kilburn KH (2001) Embryo toxicity and teratogenicity of formaldehyde. Arch Environ Health 56: 300-11.

Trocho C, Pardo R, Rafecas I, Virgili J, Remesar X, Fernandez- Lopez JA, et al (1998) Formaldehyde derived from dietary aspartame binds to tissue components in vivo. Life Sci 63(5): 337-49.

Usanmaz SE, Akarsu ES, Vural N (2002) Neurotoxic effects of acute and subacute formaldehyde exposures in mice. Envir Toxicol Pharmacol 11: 93-100.

Varfolomeev EE, Schuchmann M, Luria V, Chiannilkulchai N, Beckmann JS, Mett IL, Rebrikov D, Brodianski VM, Kemper OC, Kollet O, Lapidot TS, Soffer D, Sobe T, Avraham KB, Goncharov T, Holtmann H, Lonai P, Wallach D (1998) Targeted disruption of the mouse Caspase 8 gene ablates cell death induction by the TNF receptors, Fas/ Apo1, and DR3 and is lethal prenatally. Immunity 9: 267-276. 